\title{
A Descriptive Study on the Training and Attitude of Future Teachers towards Educational Inclusion
}

\author{
Jorge Rojo-Ramos ${ }^{1}$, Carlos Ferrera-Granados ${ }^{1}$, Manuel Fernández-Guerrero ${ }^{2}$, \\ Fernando Manzano-Redondo ${ }^{1, *(\mathbb{D}}$, Miguel Ángel Garcia-Gordillo ${ }^{3}{ }^{(D)}$, Patricia Polero ${ }^{4}$ and \\ José Carmelo Adsuar ${ }^{1}$ (D) \\ 1 Department of Health, Economy, Motricity and Education (HEME) Research Group, University of \\ Extremadura, 10003 Cáceres, Spain; jorgerr@unex.es (J.R.-R.); carlosferreragranados@gmail.com (C.F.-G.); \\ jadssal@unex.es (J.C.A.) \\ 2 Department of Didactics of Musical, Plastic and Corporal Expression, University of Extremadura, \\ 06006 Badajoz, Spain; mfernandezg@unex.es \\ 3 Faculty of Administration and Business, Universidad Autónoma de Chile, Sede Talca 3467987, Chile; \\ miguelgarciagordillo@gmail.com \\ 4 Biomechanics Research and Movement Analysis Laboratory, CENUR Litoral Norte, Universidad de la \\ República, Florida 1065, Paysandú 60000, Uruguay; patricia.polero@gmail.com \\ * Correspondence: fmanzanoa@alumnos.unex.es
}

Received: 31 July 2020; Accepted: 14 September 2020; Published: 29 September 2020

\begin{abstract}
The Spanish educational system has heterogeneous and diverse students that have increasing learning needs. All this has forced it to reinvent itself, designing and applying a model of inclusive education that serves to offer a higher quality educational response to these students. One of the main pillars for achieving this challenge is the teaching staff. The aim of this study is to evaluate the training and attitudes of future teachers to work in inclusive educational environments. The present research had a sample of 245 future teachers in the degrees of Early Childhood Education and Primary Education, who answered the Teacher Training Evaluation Questionnaire for Inclusion (CEFI-R), specific to the object of study. As the main conclusions, we obtained that the perception of future teachers towards the concept of inclusion is positive and that the training they receive is adequate, although there is room for improvement. However, there is a need to adjust the curriculum, increase the period of practice and better coordinate the actions of the members involved in the educational process.
\end{abstract}

Keywords: initial training; inclusive education; undergraduates; future teachers

\section{Introduction}

In recent years, the Spanish educational system has increasingly seen a positive exponential increase in groups of heterogeneous students, each with their peculiarities. This fact constitutes a challenge and, at the same time, a great opportunity for the school to reinvent itself and generate the necessary changes and adaptations to be able to offer a higher quality educational response adjusted to the students. The need to build a school for all, where diversity is perceived as an opportunity, is a fact that has been discussed and addressed for years [1].

Inclusion, beyond integrating students into the system, implies a modification of the educational context and in the way of influencing the specific training of teachers so that they can meet the needs of students. Previous studies [2-5] warn about the little attention that has been given to the initial training of teachers to prepare them as competent, attentive, and sensitive professionals through an inclusive model of education. 
In this context, it seems that the main barrier preventing both educational institutions and schools from being organizations attentive to diversity lies in reviewing the pre-established ideas, norms and beliefs in force in the school, as well as functioning patterns and agents involved in teaching and its associated processes [6-8].

The main lines of research on inclusive schools agree that the common denominator for improving schools, and therefore fostering inclusion within them, is the teachers and the educational practices that they develop in their initial training [3,5,6,9-13]. For example, UNESCO, within its 2030 educational program, in force since 2016 and adopted by the organization's member countries in 2015, places great emphasis on goal number four of Sustainable Development, which aims to "Ensure inclusive and equitable quality education and promote lifelong learning opportunities for all". Therefore, initial teacher training must be based on principles of inclusion and equity. This training will enable teachers to be key transmitters and promoters of student participation and learning, especially for those who may be in a situation of vulnerability. Fernández-Batanero [7] suggested that future teachers should learn teaching methods that include all students, and be aware of the different discriminatory mechanisms that are present in the classroom today. Therefore, it is certainly necessary to make effective an inclusive curriculum that responds to the different expectations and needs of the students, all discerned in heterogeneous learning environments and linking such important cross-cutting themes as citizenship, human rights, gender equity, culture of peace and non-violence and sustainable development as the main organizers of the curriculum.

Previous studies [14] agree that the content of initial teacher training and, consequently, that directed at the attention of students with different characteristics, should be the object of the disciplines of the curriculum, the development of professional pedagogical skills and abilities, as well as professional problems directed toward professional pedagogical performance.

Indeed, the need for the initial preparation of teachers in this subject is very recent. Some education systems are seeking to enrich the curriculum with topics that address educational inclusion. However, we believe that it would be desirable not only to approach content from a theoretical perspective but also to have the opportunity to extrapolate it practically to generate more significant learning in future teachers and thus to assign them tools that will help them to face future challenges. In this sense, Forlin [15] stressed that future teachers who are close to children with special educational needs during their training process show a positive attitude and are determined to be able to achieve the objective of achieving inclusive schools.

In recent years, teachers have had to adapt to the challenges involved in implementing inclusive education. Azrak [16] highlighted the appropriateness of achieving inclusive education through the implementation and action of the various educational policies so that a new approach can be considered. Globally, the Warnock Report [17] was a turning point in affirming the importance of inclusion and the individualization of education. On the other side, while in Spain teachers are governed by the Organic Law 8/2013 for the Improvement of Educational Quality, in Extremadura the Decree 228/2014 of October 2014 regulates the educational response to the diversity of the students in the Autonomous Community of Extremadura. This Decree guides and helps teachers to make the necessary adaptations and aids for educational inclusion.

Taking into account all of the above, there is no doubt about the need for initial teacher training as the key to achieving inclusive education. However, there are still some questions that need to be answered: What competences should teachers have in their initial training about inclusion? Cano [18] states that there are certain criteria on which to base training for inclusive education: pedagogy of complexity (educational problems have a multiple dimension); constructivist perspectives; integrated development (based on contributions, multiple intelligences); adaptive teaching; curricular adaptations; support networks and collaborations (teacher-families); schools as centers of improvement and diversity as a source of enrichment and stimulus for innovation.

What attitudes do future teachers show to initial training on our object of study? Several authors [19-22] state that the results obtained on the initial training of future education professionals 
point towards the manifestation of favorable attitudes by the principles and values that inclusion defends. However, it is observed that these attitudes are altered when training variables and direct experience with students with special educational needs come into play. Martínez [23] concluded that coherent and well-planned training, both initial and ongoing, is one of the factors that can lead to negative or positive attitudes of new teachers towards diversity and inclusion. Furthermore, he states that the quality of the initial training received will influence the degree of involvement and positive or reticent attitude towards the inclusion of future teachers.

Another aspect that will be considered is the sexes of future teachers. Stake and Katz [24] suggested that female teachers tended to give more verbal and non-verbal approvals to students than male teachers did. However, these results were inconsistent with numerous other studies and generally, the effects of the interaction between the sexes of teachers and students in terms of educational success are negligible [25]. It seems that the sexes of teachers and future teachers is not very important for student performance and that individual variation in school performance is much more related to personal or school factors [26].

Therefore, this study aims to evaluate how the initial training of future teachers in the Spanish educational system is related to their beliefs about educational inclusion and to know if there are differences according to the sexes of the participants.

\section{Materials and Methods}

\subsection{Participants}

The sample was made up of 245 students from the Primary and Early Childhood Education teaching degrees of the Faculty of Education at the University of Extremadura in Badajoz. The participants were selected using a non-probabilistic sampling method based on convenience sampling [27], since the subjects selected were students from the Faculty of Education who consented to participate in the study.

Table 1 shows the distribution of the participants according to sex, age, and the degree of teaching studied. Of the total number of participants, $82 \%$ (201) were women and $18 \%$ (44) were men. With regard to age, $16.7 \%$ (41) were under 20 years of age, $74.7 \%$ (183) were between 20 and 25 years of age, and $8.6 \%$ (21) were over 25 years of age. By educational degree, $58 \%$ (142) were students of Early Childhood Education and 42\% (103) were studying Primary Education.

Table 1. Distribution of research participants' demographics $(\mathrm{N}=245)$.

\begin{tabular}{cccc}
\hline Variable & Categories & $\mathbf{N}$ & $\mathbf{\%}$ \\
\hline \multirow{2}{*}{ Sex } & Men & 44 & 18 \\
& Women & 201 & 82 \\
\hline \multirow{2}{*}{ Age } & Under 20 & 41 & 16.7 \\
& Between 20 and 25 & 183 & 74.7 \\
\multirow{2}{*}{ Degree } & Over 25 & 21 & 8.6 \\
\hline \multirow{3}{*}{ Degree Year } & Early Childhood Education & 142 & 58 \\
& Primary Education & 103 & 42 \\
& First & 38 & 15.5 \\
& Second & 66 & 26.9 \\
& Third & 101 & 41.2 \\
& Fourth & 40 & 16.3 \\
\hline
\end{tabular}

\subsection{Instruments and Measures}

Socio-demographic data: For the collection of data, a questionnaire was designed through the Google Forms application with 4 socio-demographic questions (sex, age, degree, and degree year). 
In addition, a question was included regarding the self-perception of the participants about the preparation received in order to respond to the diversity of needs of the students.

Teacher training in inclusion: The CEFI-R questionnaire [28] was used, consisting of a total of 16 items, grouped in four dimensions. These dimensions have been adopted from the "Index for inclusion developing learning and participation in schools" [29] and chosen to direct thought on changing schools.

Dimension 1, "Conception of Diversity": This dimension includes the personal assessment of the concept of diversity, the place and the way in which the schooling of students is contemplated, the educational policy on which these decisions are based and, in short, the individual interpretation of inclusive education [28]. This Dimension relates to the first major theoretical basis shown by the "Index for inclusion developing learning and participation in schools" [29], "creating inclusive cultures" and its relationship to the values of diversity. For example, this Dimension 1 relates to the dimension of creating inclusive cultures in its indicators A.2.1. There are high expectations for all students and A.2.2. Staff, governors, students and parents/carers share a philosophy of inclusion. This dimension also has its theoretical basis in all the indicators related to "developing the school for all" (B.1.) belonging to the dimension of "producing inclusive policies" [29]. Dimension 1 is composed of four items that measure the beliefs of the concept of diversity, place, and form of schooling of students and the educational policy on diversity.

Dimension 2, "Methodology": "It considers the perspective from which each of the elements that make up the curriculum are defined (methodological strategies, resources, materials, communication techniques, evaluation) and whether students consider themselves prepared to do so from the perspective of inclusion" [28]. This dimension is based on the indicators belonging to dimension "Evolving inclusive practices", in which concepts, such as orchestrating learning, lessons developing, teachers planning, etc., are developed [29]. Dimension 2 consists of five items that assess aspects related to the design and development of an inclusive curriculum and whether students consider themselves prepared to do so.

Dimension 3, "Supports": "it addresses the concept of support, the role to be played by the support teacher, the potential recipients of such support and the place where it is provided and, therefore, the collaborative work between this professional and the rest of the teachers" [28]. However, the "Index for inclusion developing learning and participation in schools" [29] is based in the theory that providing support to individuals is only part of the attempt to increase the participation of students. Therefore, it adopts a far broader notion of 'support' through all the different activities that increase a school's ability to respond to student diversity. Furthermore, this dimension has its theoretical basis in the indicators of dimension "producing inclusive policies", through its "organising support for diversity" in which the different forms of existing support are shown [29]. On the other hand, it will also be related to some indicators of dimension "involving inclusive policies", such as C.1.9. Teaching assistants support the learning and participation of all students or C.2.3. Staff develop resources to support learning and participation [29]. Dimension 3 consists of four items that refer to the teacher's conception of the concept of support, the role that the support teacher should play, which students the support teacher should work with, and where the support should be developed.

Finally, Dimension 4, "Community Participation": "Community participation. It collects information about the collaborative work between the school and the rest of the community agents, as well as the use of the resources that, beyond the school premises, the environment offers us" [28]. This dimension is again closely related to the dimension of creating inclusive cultures [29], involving all educational and environmental agents. For example, with indicators A.2.3. Students are equally valued; A.2.4. Staff and students treat one another as human beings as well as occupants of a 'role'; A.2.5. Staff seek to remove barriers to learning and participation in all aspects of the school. Dimension 4 is made up of three items that allow us to measure the degree of collaboration and participation of all educational actors in the development of adequate educational practice, as well as the use of resources offered by the environment in addition to the school. 
This instrument uses a Likert scale where values range from 1 to 4 , with 1 being "Strongly Disagree", 2 "Partially Disagree", 3 "Partially Agree" and 4 "Strongly Agree".

Prior to the analysis, the indirect items were reversed; a higher score implies greater synchrony with an adequate "Conception of diversity" (dimension 1), greater consistency with a "Methodology" (dimension 2) suitable for inclusion, an adjusted conception of "Support" (dimension 3) and a correct concordance with correct "Community Participation" (dimension 4).

This questionnaire presents good evidence of reliability and validity. The researchers [28] examined the degree of internal consistency using Cronbach's alpha and the CEFI-R and each dimension showed reliability estimations above the 0.70 threshold.

\subsection{Methods}

Both the socio-demographic questionnaire and the CEFI-R were prepared and administered in digital format, since the e-questionnaires allow greater savings in costs and time and are quite precise, obtaining a higher rate of return and rapid delivery [30]. The responses of the participants were stored directly in a spreadsheet, which facilitated the transformation of the responses for subsequent statistical analysis. The data collection took place between mid-January and early March 2020, during the course of the academic year.

To access the sample, the delegates of each of the courses were first contacted and given a document with the information on the objective of the study, as well as a URL link to the questionnaire that was to be extended to the rest of the class group.

The participants in the study received the same detailed information at the beginning of the questionnaire about the purpose of the questionnaire and that their data would be treated anonymously, so if they wished to continue, they had to accept the informed consent by checking the box provided for this purpose. The average time needed to answer the questionnaire was $10 \mathrm{~min}$.

\subsection{Statistical Analysis}

The analysis of the collected data was performed with the Statistical Package for Social Sciences (SPSS) version 23.0 for MAC.

Pearson's Chi-square test was used to analyze the differences between the item "On a general level, I consider that my training at university has prepared me, or is preparing me, to respond to the diversity of needs of my students" and the variables of degree and sex (Table 2).

Table 2. Distribution of frequencies in the item responses according to sex and degree $(\mathrm{N}=245)$.

\begin{tabular}{|c|c|c|c|c|c|}
\hline & \multirow[t]{2}{*}{ Item } & & \multicolumn{3}{|c|}{$\begin{array}{l}\text { "On a General Level, I Consider That My Training at } \\
\text { University Has Prepared Me, or Is Preparing Me, to } \\
\text { Respond to the Diversity of Needs of My Students" }\end{array}$} \\
\hline & & & Yes & No & $p$ \\
\hline \multirow{6}{*}{ Sex } & \multirow{2}{*}{ Men } & $\mathrm{N}$ & 27 & 17 & \multirow{6}{*}{0.38} \\
\hline & & $\%$ & 19.9 & 15.6 & \\
\hline & \multirow{2}{*}{ Women } & $\mathrm{N}$ & 109 & 92 & \\
\hline & & $\%$ & 80.1 & 84.8 & \\
\hline & \multirow{2}{*}{ Total } & $\mathrm{N}$ & 136 & 109 & \\
\hline & & $\%$ & 55.5 & 44.5 & \\
\hline \multirow{6}{*}{ Degree } & \multirow{2}{*}{ Early Childhood Education } & $\mathrm{N}$ & 73 & 69 & \multirow{6}{*}{0.13} \\
\hline & & $\%$ & 53.7 & 63.3 & \\
\hline & Primary Fducation & $\mathrm{N}$ & 63 & 40 & \\
\hline & Primary Equcation & $\%$ & 46.3 & 36.7 & \\
\hline & \multirow{2}{*}{ Total } & $\mathrm{N}$ & 136 & 109 & \\
\hline & & $\%$ & 55.5 & 44.5 & \\
\hline
\end{tabular}


To analyze if the variables met the assumption of normality, Kolmogorov Smirnov's test was used, which indicated that the assumption was not met, so it was decided to use non-parametric tests. Subsequently, the Mann-Whitney $U$ test was used to analyze the relationships between the different dimensions: a degree and the sex of the sample (Tables 3 and 4).

Table 3. Descriptive analysis and differences by sex and degree of the items of the questionnaire.

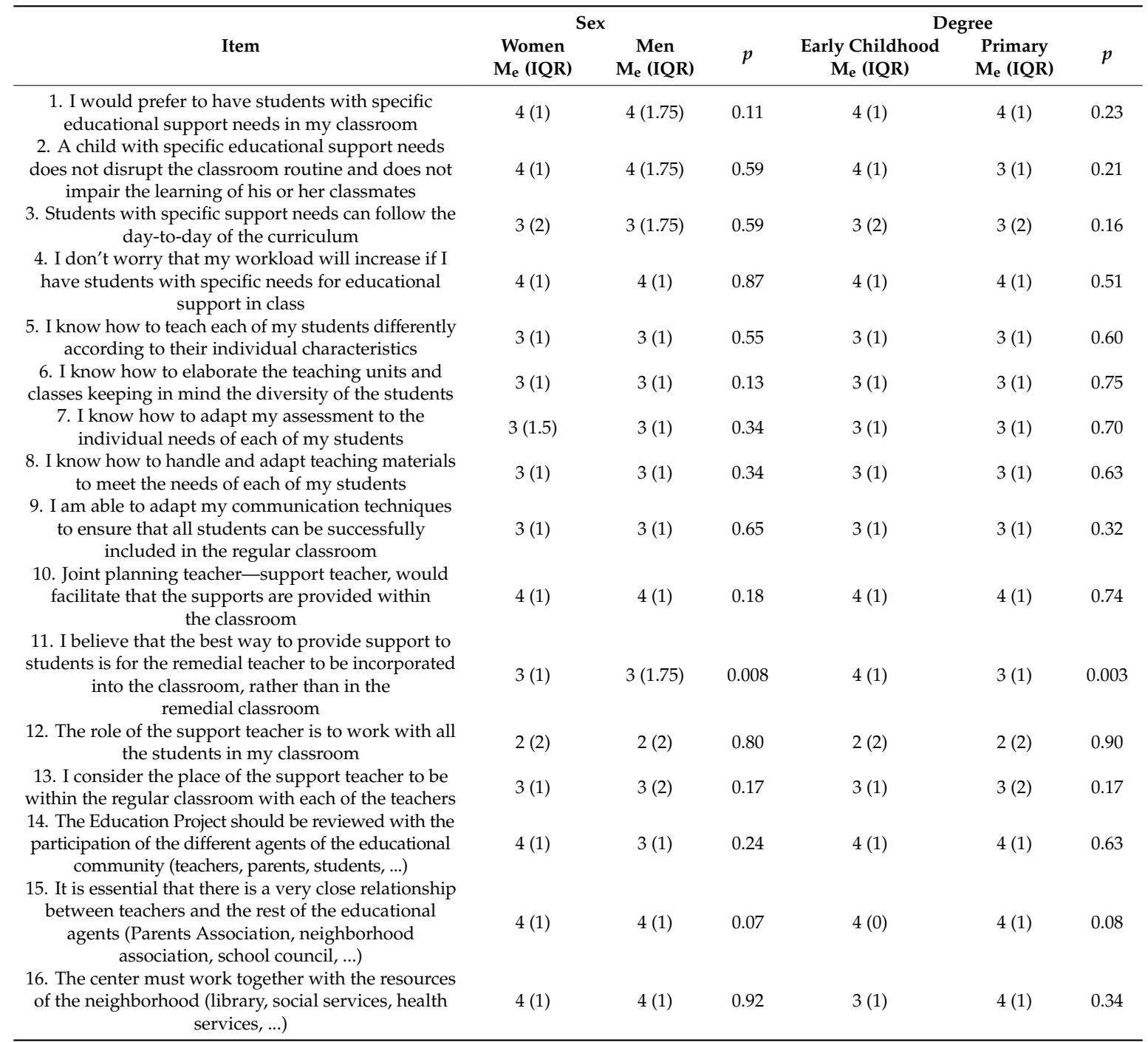

Note: $\mathrm{Me}=$ median value; IQR = Interquartile Range. Each score obtained is based a Likert scale (1-4): 1 being "Strongly Disagree", 2 "Partially Disagree", 3 "Partially Agree" and 4 "Strongly Agree".

Table 4. Descriptive analysis and differences of each dimension of the questionnaire.

\begin{tabular}{lc}
\hline \multicolumn{1}{c}{ Dimensions } & Me (IQR) \\
\hline 1. Conception of Diversity & $3.5(0.75)$ \\
2. Methodology & $3(1)$ \\
3. Supports & $3(0.8)$ \\
4. Community Participation & $3.66(0.92)$ \\
\hline
\end{tabular}

Note: Me = median value; IQR = Interquartile Range. Each score obtained is based a Likert scale (1-4): 1 being "Strongly Disagree", 2 "Partially Disagree", 3 "Partially Agree" and 4 "Strongly Agree".

The scores of the four components ("Conception of Diversity", "Methodology", "Supports" and "Community Participation") were obtained from the median (Me) value of each of the items that made up each dimension. The data are presented as Median and Interquartile Range (IQR) (Tables 3 and 4). 
The correlation coefficient between the dimensions and the different age ranges was made using the Spearman test (Table 5).

Table 5. Correlations between the dimensions and the age group variable.

\begin{tabular}{cc}
\hline Dimensions & Age $\rho(p)$ \\
\hline Conception of diversity & $-0.15(0.01)$ \\
Methodology & $-0.11(0.06)$ \\
Supports & $-0.04(0.52)$ \\
Community Participation & $0.05(0.40)$ \\
\hline
\end{tabular}

Note: The correlation is significant at the ${ }^{* *} p<0,01 ;{ }^{*} p<0,05$. Each score obtained on the dimensions is based on a Likert scale (1-4): 1 being "Strongly Disagree", 2 "Partially Disagree", 3 "Partially Agree" and 4 "Strongly Agree".

In addition, reliability was calculated for each of the dimensions using Cronbach's Alpha statistician. In line with Nunally and Berstein [31], composite reliability values of 0.60 to 0.70 are acceptable in exploration, while values between 0.70 and 0.90 can be regarded as satisfactory.

\section{Results}

Table 2 and Figure 1 show the distribution of frequencies in the responses to the item "On a general level, I consider that my training at university has prepared me, or is preparing me, to respond to the diversity of needs of my students" according to sex and the degree studied. The results show that $55.5 \%(n=136)$ of the participants answered positively and $44.5 \%(n=109)$ denied having received or being prepared to meet the diversity of student needs. The results show that there is no significant association between this item and $\operatorname{sex}\left(\chi^{2}=0.74\right.$; Contingency coefficient $\left.=0.055 ; p=0.38\right)$ nor with the degree variable $\left(\chi^{2}=2.30\right.$; Contingency coefficient $\left.=0.096 ; p=0.13\right)$.

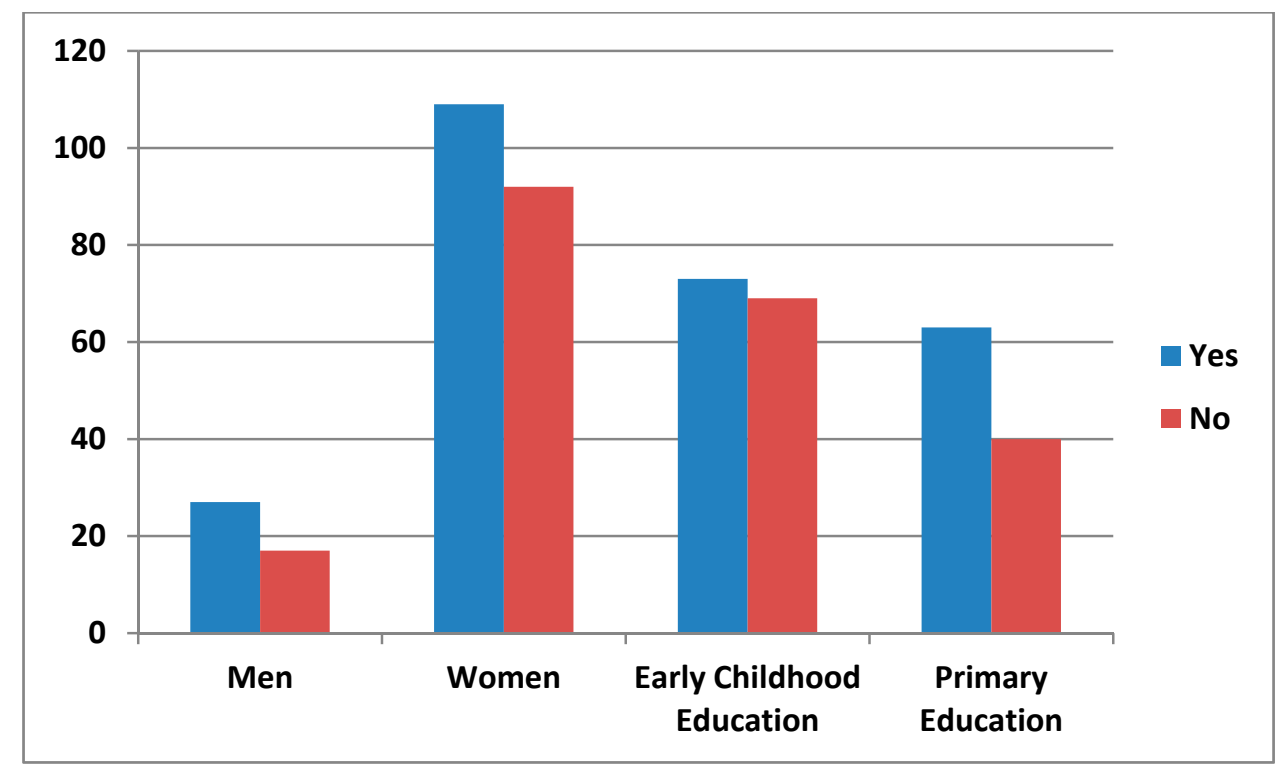

Figure 1. Distribution of $\mathrm{N}$ in the item responses according to sex and degree.

Table 3 shows the descriptions and differences by sex and degree for each of the items that make up the CEFI-R questionnaire. Similarly, Table 4 and Figure 2 show the descriptive analysis and the differences grouped by each dimension of the questionnaire. 


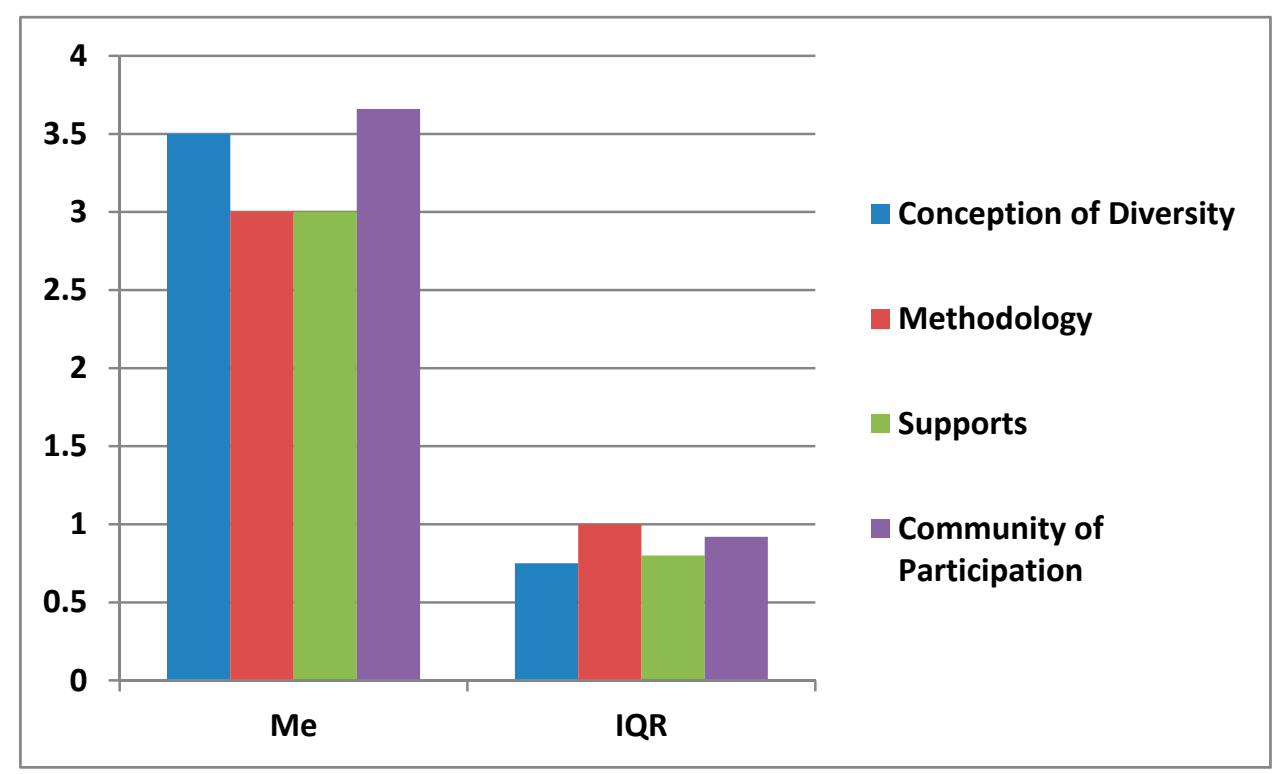

Figure 2. Median and IQR differences between each dimension.

The indirect items are reversed: a higher score implies greater synchrony with each dimension.

In relation to the first dimension "Conception of diversity", the participants in the study show a score Median $(\mathrm{Me})=3.5(\mathrm{IQR}=0.75)$. The scores are similar for men and women $\mathrm{Me}_{\mathrm{Men}}=3.5(\mathrm{IQR}=1)$, $\mathrm{Me}_{\text {Women }}=3.5(\mathrm{IQR}=0.75)$, with no significant differences observed when comparing between sex $(p=0.64)$, nor by degree $(p=0.14)$. With respect to the items that make up this first dimension, the highest scores (greater synchrony with an adequate conception of diversity) were obtained in "I would prefer to have students with specific educational support needs in my classroom" (Me $=4 ; \mathrm{IQR}=1$; degree $(p=0.23)$; sex $(p=0.11)$ ), "A child with specific educational support needs does not disrupt the classroom routine and disrupts the learning of his or her peers" $(\mathrm{Me}=4 ; \mathrm{IQR}=1$; degree $(p=0.21)$; sex $(p=0.59))$ and "I am not concerned that my workload will increase if I have students with specific educational support needs in my class" (Me $=4 ; \mathrm{IQR}=1$; degree $(p=0.51)$; sex $(p=0.87))$. However, a lower score was obtained for the item "Students with specific support needs can follow the day-to-day curriculum" ( $\mathrm{Me}=3 ; \mathrm{IQR}=2$; degree $(p=0.16)$; $\operatorname{sex}(p=0.59))$.

The score obtained in the second dimension "Methodology" obtained the following results $\mathrm{Me}=3$ $(\mathrm{IQR}=1), \mathrm{Me}_{\mathrm{Men}}=2.9(\mathrm{IQR}=0.8), \mathrm{Me}_{\mathrm{Women}}=3(\mathrm{IQR}=1)$, obtaining no significant differences either by sex $(p=0.54)$ or by degree $(p=0.60)$. The scores obtained in each of the items of this second dimension are for item 5 "I know how to teach each of my students differently according to their individual characteristics" (Me $=3 ; \mathrm{IQR}=1$; degree $(p=0.60)$; $\operatorname{sex}(p=0.55))$; for item 6 "I know how to elaborate the teaching units and classes bearing in mind the diversity of the students" (Me $=3 ; \mathrm{IQR}=1$; degree $(p=0.75)$; $\operatorname{sex}(p=0.13))$; for item 7 "I know how to adapt my assessment to the individual needs of each of my students" ( $\mathrm{Me}=3$; IQR $=1$; degree $(p=0.70)$; $\operatorname{sex}(p=0.34)$ ); for item 8 "I know how to handle and adapt the teaching materials to meet the needs of each of my students" $(\mathrm{Me}=3$; $\mathrm{IQR}=1$; degree $(p=0.63)$; sex $(p=0.34))$; for item 9 "I am able to adapt my communication techniques to ensure that all learners can be successfully included in the regular classroom" $(\mathrm{Me}=3 ; \mathrm{IQR}=1$; degree $(p=0.32)$; sex $(p=0.65))$. Therefore, we can state that in this dimension of "Methodology" no significant differences have been obtained in any of the items either by sex or by degree.

In the third dimension "Supports", the following scores were obtained: $\mathrm{Me}=3$ (IQR $=0.8$ ); $\mathrm{Me}_{\mathrm{Men}}=3(\mathrm{IQR}=0.75) ; \mathrm{Me}_{\text {Women }}=3.25$ (IQR = 0.75). No significant differences were obtained either by sex $(p=0.82)$ or by degree $(p=0.16)$ with respect to this dimension. The highest score was obtained in item 10 "Joint teacher-support teacher planning would facilitate support within the classroom" $(\mathrm{Me}=4$; $\mathrm{IQR}=1$; degree $(p=0.74)$; $\operatorname{sex}(p=0.18))$, and the item with the lowest score was 12 , "The function of the support teacher is to work with all students in my classroom" $(\mathrm{Me}=2 ; \mathrm{IQR}=2$; degree $(p=0.90)$; 
$\operatorname{sex}(p=0.80))$. If we find significant differences by sex and degree in item 11 "I believe that the best way to provide support to students is for the remedial teacher to be incorporated into the classroom, rather than in the remedial classroom" obtaining as results $\left(\mathrm{Me}_{\mathrm{Men}}=3 ; \mathrm{IQR}=0.75 ; \mathrm{Me}_{\text {Women }}=3.25\right.$; $\mathrm{IQR}=0.75 ;$ MePrimary $_{1}=3 ; \mathrm{IQR}=1 ; \mathrm{Me}_{\text {Early Childhood }}=3.25 \mathrm{IQR}=0.75 ;$ degree $\left.(p=0.03) ; \operatorname{sex}(p=0.08)\right)$.

Finally, in the fourth dimension "Community Participation", the sample offers Me $=3.66$ $(\mathrm{IQR}=0.92) ; \mathrm{Me}_{\mathrm{Men}}=3.66(\mathrm{IQR}=0.75), \mathrm{Me}_{\text {Women }}=3.66(\mathrm{IQR}=0.7)$. In this case, we also did not obtain significant differences in terms of degree $(p=0.21)$ or sex $(p=0.21)$. The scores obtained in each of the three items of this dimension are identical $(\mathrm{Me}=4 ; \mathrm{IQR}=1)$, and no significant differences were found in any of these items in degree or in sex: for item 14 "The Education Project should be reviewed with the participation of the different agents of the educational community (teachers, parents, students...)" (degree $(p=0.63)$; sex $(p=0.24)$ ); for item 15 "It is essential that there is a very close relationship between teachers and the rest of the educational agents (Parents Association, neighborhood association, school council...)" (degree $(p=0.08)$; sex $(p=0.07)$ ); for item 16 "The center must work together with the resources of the neighborhood (library, social services, health services, ...)" (degree $(p=0.34)$; sex $(p=0.92))$.

The indirect items are reversed-a higher score implies greater synchrony with each dimension.

Then, Table 5 and Figure 3 show the correlations between the different dimensions of the CEFI-R questionnaire and age. The results indicate that in dimension 1 "Conception of diversity", there is a significant low and inverse correlation with age; as the age range increases, the dimension 1 score decreases $(\varrho=-0.15 ; p=0.01)$. Similar results are shown for the "Methodology" dimension, which again showed a low and inverse correlation $(\varrho=-0.11 ; p=0.06)$. The same is true for the "Supports" dimension, where there is a low and inverse but not significant correlation $(\varrho=-0.04 ; p=0.52)$. Finally, the results of the dimension "Community Participation ", show a low and direct correlation with age $(\varrho=0.05 ; p=0.40)$.

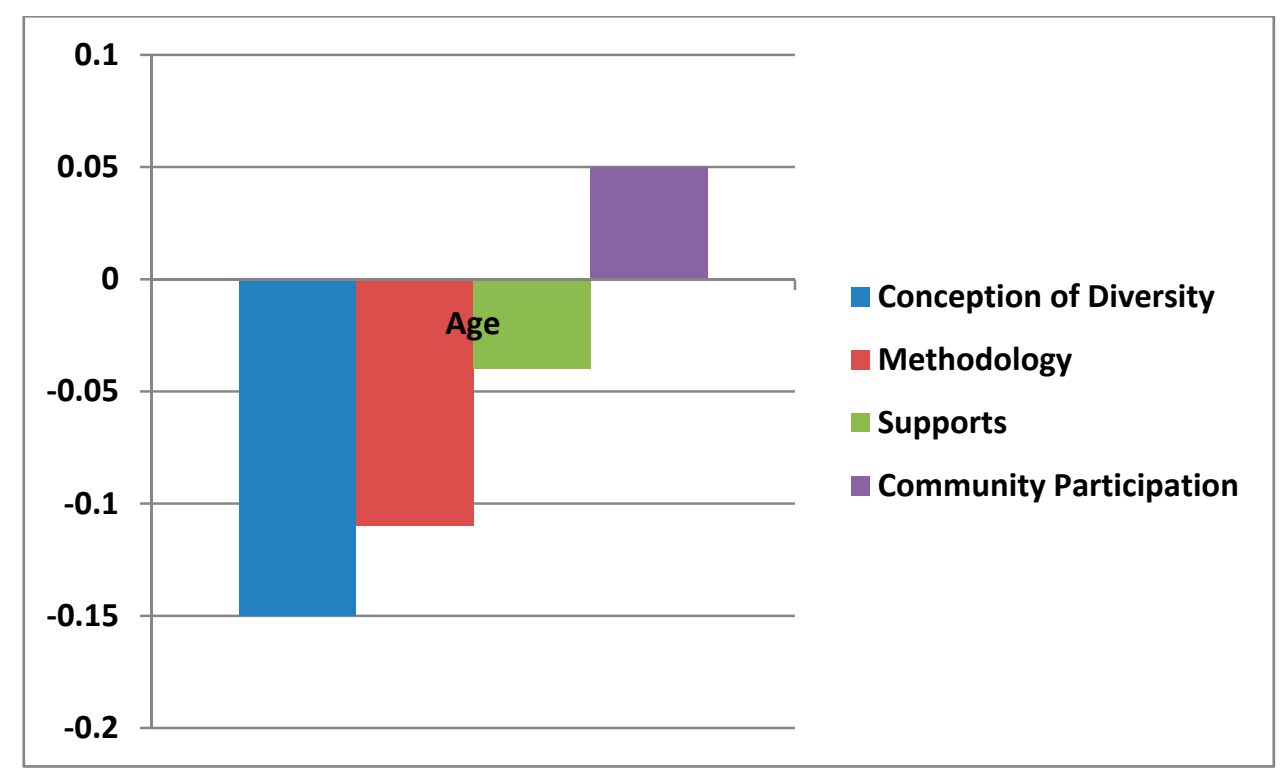

Figure 3. Differences in correlations between the dimensions and the age group variable.

The indirect items are reversed: a higher score implies greater synchrony with each dimension.

Finally, the results for reliability for each of the dimensions that make up the CEFI-R questionnaire were: $\mathrm{a}^{1}=0.68 ; \mathrm{a}^{2}=0.89 ; \mathrm{a}^{3}=0.62$ and $\mathrm{a}^{4}=0.70$, with all values being acceptable, above 0.60 .

\section{Discussion}

This study describes the perception of future Early Childhood and Primary Education teachers in the Spanish educational system about the initial training they receive in inclusive education in the 
faculty and their attitudes towards this concept. For this purpose, the validated instrument CEFI-R was used, with a multidimensional character, composed of a total of 16 items grouped into four dimensions (Conception of Diversity; Methodology; Support; Community Participation). This questionnaire made it possible to effectively and reliably measure the attitudes, competencies, skills, and abilities of future teachers to the concept of inclusive education.

Previously, future teachers had to respond to the item "On a general level, I consider that my training at university has prepared me, or is preparing me, to respond to the diversity of needs of my students" (Table 2). The results obtained for this item had a positive response of $55.5 \%(\mathrm{~N}=136)$, as opposed to a negative response of $44.5 \%(\mathrm{~N}=109)$. Our results coincide with those reported in several previous studies [5,19-22], which seems to indicate that, at a general level, the concept of educational inclusion is effectively addressed in the different curriculum of the Early Childhood and Primary Education degrees taught at the Faculty of Education in Badajoz.

By dimensions (Tables 3 and 4), the results obtained in the first one "Conception of diversity" $(\mathrm{Me}=3.5)$, we highlight the items with higher score values: "I would prefer to have students with specific educational support needs in my classroom"; "A child with specific educational support needs does not disrupt the classroom routine and does not impair the learning of his or her classmates"; " I don't worry that my workload will increase if I have students with specific needs for educational support in class". The results of this research reinforce the conclusions of those studies that state that future teachers generally show positive attitudes about educational inclusion [5,19-22].

On the contrary, we obtained much lower values for the item "Students with specific support needs can follow the day-to-day of the curriculum". This leads us to conclude, in line with Duk and Loren [32] that it is necessary at present to make the necessary adjustments to the curriculum to avoid accentuating inequalities of origin and those imposed by the education system itself in order to be able to respond adequately to the needs of students who require it.

The results show in the second dimension, "Methodology" $(\mathrm{Me}=3)$, that future teachers feel competent to teach and make the relevant adaptations according to the individual characteristics of the students, would know how to develop curricular and didactic material to respond to such needs and would know how to adapt the necessary communication techniques that students with special educational needs require. However, these results must be analyzed in a cautious way, and take into account the references that Casanova and Rodríguez establish [33]. They comment that, although new teachers are able to make the necessary curricular adaptations in school contexts, many times they are not able to carry out an adequate balance between theory and practice, ending up with inadequate, unattractive, and even exclusive teaching strategies for students. For this reason, we believe that a more theoretical-practical approach is necessary for the initial training of future teachers that approaches an adequate reality. We, therefore, agree with Forlin [15], who in one of his research articles points out that when future teachers are close to children with special educational needs during their training process, they show a positive and determined attitude in being able to achieve the objective of achieving inclusive schools, acquiring the necessary experience in practical matters and not so much theory without knowing how to adapt.

Important data and results are obtained in dimension 3 "Supports" $(\mathrm{Me}=3)$. Of the items selected for this dimension, the most positive values are found in: "Joint planning teacher - support teacher, would facilitate that the supports are provided within the classroom". This indicates that future teachers approve of the inclusion of the support teacher within the ordinary classroom, due to its multiple benefits, as it offers us, in Cladellas et al. [34]: "It allows two teachers to have a shared knowledge of the same group to adapt the programming and methodology to the needs of the group and also to guarantee personalized attention,... It is necessary to identify the moments when a second teacher works in the classroom"; "it is necessary to choose the moments of intervention and plan them jointly establishing complementary functions between the two teachers, with an established, but not rigid, distribution of the tasks to be carried out with the students". 
Finally, about dimension 4, "Community Participation" $(\mathrm{Me}=3.66)$, the results obtained are all directed towards the need for participation of all the agents involved in education, working in synergy with families to be able to offer an inclusive education that meets the needs and demands of today's students.

We conclude that the results obtained in the four dimensions analyzed in the study, taking the Likert scale (1-4) as a reference, are quite positive, obtaining values between 3 and 4 in each of them. Thus, there are no significant differences in each dimension according to the items between men and women (Table 3), nor in the total by grouped dimensions, obtaining values between 3 and 3.66 (Table 4 , Figure 2). As well as Burusic et al. [25], it is confirmed that the assumption that differences in school performance are related to the gender of teachers cannot be supported within elementary education. However, in this case, differences can be observed in the number of male and female participants (Table 1), with $82 \%$ women and $18 \%$ men, following the trend which states that teaching is still largely considered a feminine domain [35].

Otherwise, by analyzing the correlations between the dimensions and the age group variable (Table 5, Figure 3), on dimensions 1 and 2, there are significant low and inverse correlations with age; as the age range increases, dimensions 1 and 2 scores decrease. For dimension 3 , there is a low and inverse correlation but, in this case, it is not significant. However, dimension 4 again shows a low but direct correlation, increasing the score as the age range increases.

Concerning the reliability of the instrument in our sample, acceptable indices were obtained in all four dimensions, with the lowest scores in dimension 1 and 3, coinciding with the results obtained by González-Gil et al. [28], and these data should, therefore, be taken with caution. However, and also by what was reported by the same authors [28], it is in dimension 2 (Methodology) where the best reliability index was obtained $(\mathrm{a}=0.89)$.

We learn from the results in the same way that, in the approach of Inclusive Education, we cannot understand the word participation of the different actors without talking about coordination. In this way, we consider that it would be appropriate to propose different types of collaboration to achieve inclusion: Inter-institutional (collaboration projects between schools), Inter-professional (between schools and professionals), Inter-services (between school and educational and/or social services in the social environment), between students (collaboration in the classroom) and with the family community (school-community). Therefore, in this process of inclusion, the contribution of all is needed to achieve the objective.

Concerning all that has been addressed, we conclude by commenting that, although the initial training of future teachers in the field of inclusive education is increasingly greater and appropriate to new needs, it must be constantly reviewed. Thus, it will be possible to adjust those necessary nuances that will help us not only to intervene, but also to be proactive and generate successful skills in the new teachers, who, aware of the heterogeneity of the new students and the need to adapt, must use all the tools available to them to be efficient in their educational work.

It should be noted that this study has certain limitations that we should consider. One of them is related to the method of sample selection since it has not been carried out according to randomized procedures. It was limited to students of the Degrees of Early Childhood Education and Primary Education at the University of Extremadura of the Faculty of Badajoz. We also considered that perhaps obtaining a larger sample would help to obtain more significant data and thus an improvement in external validity. In the same way, to complete the study, an analysis of the different attentions produced by the management and pedagogical teams in the educational centers about our object of study, the educational inclusion, could be approached. Likewise, it is possible that the participants' self-ratings about educational inclusion do not fully correspond to the actual inclusion experiences of their students.

As future lines of research, once the present study has been carried out, we offer the scientific community the possibility of extending our study to other territories, as well as being able to respond to the various questions about the existence and effectiveness of the establishment of protocols and 
didactic and curricular material in the different educational centers and their treatment in the Centre's Educational Projects by the regulations in force in the Autonomous Community of Extremadura.

\section{Conclusions}

After the analysis and discussion of the results, and taking into account our object of study, we can conclude that the attitudes of future teachers towards inclusion are very positive, finding no significant differences between men and women participants and valuing a motivated, sensitive and aware of the difficulty of the teaching process in the school of the 21st century. Similarly, the results show that around the initial training addressed in the curriculum of the Faculty of Education of Badajoz in relation to the inclusive methodology are, in general, sufficient and necessary, in order to generate an adequate preparation of the future teachers to be able to respond to the diversity of needs.

However, we must also conclude that a review of the current academic curriculum is required in order to avoid accentuating the inequalities of origin of students with special educational needs and those already created by the education system itself. We also infer that it is vital to increase the practice time of future teachers and their relations with students, because on many occasions there are excessive theoretical constructs without practical applicability that do not provide teachers with tools to offer a quality educational response, implementing, for example, appropriate and attractive teaching strategies in the classroom.

On the other hand, the study highlights the need to include educational support personnel, such as Therapeutic Pedagogy (TP) or Hearing and Language (HL) teachers, and even to work with other external professionals as social integrators to play an interdisciplinary role within the regular classroom and not in specific classrooms, as far as possible. Likewise, it is established as a priority and essential to work on synergies between family and school as a fundamental pillar for inclusion.

Finally, as a generalization of the work to be applied in different territories, to affirm that the groups of students related to the teaching show a very positive attitude and a good preparation for the inclusive methodology. However, they believe that the educational system should increase the time of practice with these students and develop educational strategies in the classes, thus avoiding creating inequalities.

Author Contributions: Conceptualization, J.R.-R., C.F.-G., M.F.-G., F.M.-R., M.Á.G.-G., P.P. and J.C.A.; Formal analysis, J.R.-R. and J.C.A.; Funding acquisition, M.Á.G.-G. and P.P.; Methodology, J.R.-R., C.F.-G., M.F.-G., F.M.-R., M.Á.G.-G., P.P. and J.C.A.; Software, J.R.-R., C.F.-G., M.F.-G., F.M.-R. and J.C.A.; Supervision, J.C.A.; Writing — original draft, J.R.-R., C.F.-G., M.F.-G., F.M.-R., M.Á.G.-G., P.P. and J.C.A.; Writing—review \& editing, J.R.-R., F.M.-R. and J.C.A. All authors have read and agreed to the published version of the manuscript.

Funding: This research was funded by Universidad de la República, Uruguay.

Acknowledgments: The authors would like to acknowledge the participants and professionals who helped and allowed the access for this study.

Conflicts of Interest: The authors declare no conflict of interest.

\section{References}

1. Sapon-Shevin, M. La inclusión real: Una perspectiva de justicia social. Rev. Investig. Educ. 2014, 11, 71-85.

2. Acedo, C. Preparing teachers for inclusive education. Prospects 2011, 41, 301.

3. Colmenero, M.; Pantoja, A.; Pegalajar, M. Percepciones del alumnado sobre atención a la diversidad en la formación inicial del profesorado de Educación Secundaria. Rev. Complut. Educ. 2015, 26, 101-120.

4. Roldán, S.M.; Holland, C. Educación especial e inclusión: Aportaciones desde la investigación. Rev. Educ. Pedagog. 2010, 22, 31-43.

5. Sharma, U.; Jacobs, D.K. Predicting in-service educators' intentions to teach in inclusive classrooms in India and Australia. Teach. Teach. Educ. 2016, 55, 13-23.

6. Ahmmed, M.; Sharma, U.; Deppeler, J. Variables affecting teachers' intentions to include students with disabilities in regular primary schools in Bangladesh. Disabil. Soc. 2014, 29, 317-331. 
7. Fernández Batanero, J.M.; Benítez Jaén, A.M. Respuesta educativa de los centros escolares ante alumnado con sindrome de Down. Percepciones familiares y docentes. Profr. Rev. Curric. Form. Profr. 2016, 20, $296-311$.

8. Weiß, S.; Kollmannsberger, M.; Lerche, T.; Oubaid, V.; Kiel, E. The pedagogic signature of special needs education. Eur. J. Spec. Needs Educ. 2014, 29, 200-219.

9. Ainscow, M.; Sandill, A. Developing inclusive education systems: The role of organisational cultures and leadership. Int. J. Incl. Educ. 2010, 14, 401-416.

10. Echeita, G.; Verdugo, M.; Sandoval, M.; Simón, C.; López, M.; González-Gil, F.; Calvo, M. La opinión de FEAPS sobre el proceso de inclusión educativa. Siglo Cero. Rev. Española Sobre Discapac. Intelect. 2008, 39, 26-50.

11. Carreres, A.L.; Sánchez, P.A. Evaluación de las prácticas educativas del profesorado de los centros escolares: Indicadores de mejora desde la educación inclusiva. Reice. Rev. Iberoam. Sobre Calid. Efic. Cambio Educ. 2010, 8, 96-109.

12. Muntaner, J.J. Estándares e Indicadores Para Analizar la Calidad de Vida del Alumnado Con Discapacidad en su Proceso Educativo; Universitat de les Illes Balears: Illes Balears, Spain, 2010.

13. Torres, J.A.; Fernández, J.M. Promoviendo escuelas inclusivas: Análisis de las percepciones y necesidades del profesorado desde una perspectiva organizativa, curricular y de desarrollo profesional. Rev. Electrónica Interuniv. Form. Profr. 2015, 18, 177-200. [CrossRef]

14. Cobas, L.; Granados, L.; Cok, A. Enseñanza Primaria: Por una Educación Inclusiva, Equitativa y de Calidad Para Igualar las Oportunidades de Desarrollo Desde la Formación Profesional. Curso Internacional. In Proceedings of the Simposio: VIII Congreso Internacional Educación y Pedagogía Especial y V Simposio de la Educación Primaria.“Educación Inclusiva. Retos Y Desafíos”, La Habana, Cuba, 11-15 June 2018.

15. Forlin, C. Future Directions for Inclusive Teacher Education: An International Perspective; Routledge: Abingdon, UK, 2012.

16. Azrak, A.M. Sobre educación inclusiva: Enfoque de derechos humanos y contribuciones de la psicología. Anu. Investig. 2017, 24, 61-68.

17. Warnock, M. Informe Warnock. 1978. Available online: https://www.ugr.es/ \{\}aula_psi/INFORME_ WARNOCK_.htm (accessed on 31 July 2020).

18. Cano, A.J.R. Formación docente y su relación con los contextos inclusivos. Rev. Int. Apoyo A Inclusión Logop. Soc. Multicult. 2018, 4, 160-171.

19. Álvarez, J.L.; Buenestado, M. Predictores de las actitudes hacia la inclusión de alumnado con necesidades educativas especiales en futuros profesionales de la educación. Rev. Complut. Educ. 2015, 26, 627-645.

20. López-Torrijo, M.; Mengual-Andrés, S. An attack on inclusive education in Secondary Education. Limitations in initial teacher training in Spain. J. New Approaches Educ. Res. (Naer J.) 2015, 4, 9-17. [CrossRef]

21. McKay, L. Beginning teachers and inclusive education: Frustrations, dilemmas and growth. Int. J. Incl. Educ. 2016, 20, 383-396. [CrossRef]

22. Rodríguez-Gómez, D.; Armengol, C.; Meneses, J. La adquisición de las competencias profesionales a través de las prácticas curriculares de la formación inicial de maestros. Rev. Educ. (Madr.) 2017, 376, 229-243.

23. Martínez, T.S. La formación inicial y su incidencia en la educación especial. Educ. Espec. 1996, 1, $389-406$.

24. Stake, J.E.; Katz, J.F. Teacher-pupil relationships in the elementary school classroom: Teacher-gender and pupil-gender differences. Am. Educ. Res. J. 1982, 19, 465-471. [CrossRef]

25. Burusic, J.; Babarovic, T.; Seric, M. Differences in elementary school achievement between girls and boys: Does the teacher gender play a role? Eur. J. Psychol. Educ. 2012, 27, 523-538. [CrossRef]

26. Babarović, T.; Burušić, J.; Šakić, M. Uspješnost predviđanja obrazovnih postignuća učenika osnovnih škola Republike Hrvatske. Društvena Istraživanja Časopis Za Opća Društvena Pitanja 2009, 18, 673-695.

27. Salkind, N.J. Métodos de Investigación; Pearson Educación: London, UK, 1999.

28. González-Gil, F.; Martín-Pastor, E.; Baz, B.O. Están los futuros profesores formados en inclusión: Validación de un cuestionario de evaluación. Aula Abierta 2017, 46, 33-40. [CrossRef]

29. Booth, T.; Ainscow, M. Index for Inclusion: Developing Learning and Participation in Schools; Centre for Studies on Inclusive Education: Bristol, UK, 2002.

30. Anderson, T.; Kanuka, H. e-Research; Allyn \& Bacon: Boston, MA, USA, 2002.

31. Nunnally, J.; Bernstein, I. Elements of statistical description and estimation. Psychom. Theory 1994, 3, 127.

32. Duk, C.; Loren, C. Flexibilización del currículum para atender la diversidad. Rev. Latinoam. Inclusión Educ. 2010, 4, 187-210. 
33. Casanova, M.A.; Rodríguez, H.J. La Inclusión Educativa, un Horizonte de Posibilidades; Editorial La Muralla: Madrid, Spain, 2009.

34. Cladellas, J.A.; Reixach, M.C.; i Ballús, E.B. Estrategias Organizativas de Aula: Propuestas Para Atender la Diversidad; Grao: Castellón, Spain, 2009; Volume 8.

35. Carrington, B.; Skelton, C. Re-thinking'role models': Equal opportunities in teacher recruitment in England and Wales. J. Educ. Policy 2003, 18, 253-265. [CrossRef]

(C) 2020 by the authors. Licensee MDPI, Basel, Switzerland. This article is an open access article distributed under the terms and conditions of the Creative Commons Attribution (CC BY) license (http://creativecommons.org/licenses/by/4.0/). 